\title{
The Relationship Between Phonemics And Segmentation In English
}

\author{
May Stephan Rezqallah* \\ College of Languages, University of Baghdad, Baghdad, Iraq
}

Corresponding Author: May Stephan Rezqallah, E-mail: sudadjanabi@yahoo.com

\section{ARTICLE INFO}

Article history

Received: January 06, 2018

Accepted: March 19, 2018

Published: June 30, 2018

Volume: 9 Issue: 3

Advance access: May 2018

Conflicts of interest: None

Funding: None

Key words:

Segmentation,

Phonemics,

Phonetics,

Phonology,

Phonemes,

Realizations,

Segmental Approach

\begin{abstract}
With the advent of communication facilities, most of our students are enthusiastic to get highly acquainted with rhythmical languages; one of these languages is English. Students prefer to speak the language more than to ${ }^{\circledR}$ write a composition, or get in touch with its grammar. In other words, a question is raised "how can we learn English through its spoken form represented in conversations and dialogues ?" It is not an easy task to teach phonetics and phonology concepts to Iraqi college students; the concepts of visualization of those students; the distinctions between phonemes and segments. So far, they are keen to communicate in English, still their demand and study are to tackle the basic notions. In other words, those students have to get in perceiving the e.g., difference between production and pronunciation; the air stream mechanism participation to make them cope with the precise production and pronunciation. This paper is to reveal the importance of segmentation and phonemics of English for Iraqi students (undergraduates \& postgraduates). In other word it is done in order to cope with such inquiry, the linguistic subjects - phonetics and phonology are taught with so many details; i.e., students have to know that letters are written and sounds are spoken. The result would reveal the accents and dialects of English; overseas students are instructed to get used to the teachable variety of English-hence $\mathrm{BBC}$.
\end{abstract}

\section{INTRODUCTION}

An important task in any science is the classification of the units of the material with which that science operates. This classification can be done in different ways and on different grounds according to the purpose that the scientist has in View, and the criteria of the success of classification lay in its adequacy and usefulness in answering that purpose. Classification presupposes first an analysis to isolate units to be classified, and second methods of description of these units which enables some to be distinguished from others (Brosnahan and Malmberg, 1970: 74). According to the subject matter, i.e. phonemics and segmentation, the scientific area represents both phonetics and phonology (or phonemics) and what needs to be classified is the continuum of speech into small units termed as phonemes or segments.

These two terms used interchangeably in some books without giving a justification for why phoneticians have classified the speech continuum into phonemes and segments; therefore, there is an overlap and misusing the terms. Nevertheless, the fact is they are quite distinctive and each one "has its own description, which enables us to decide whether this is a phoneme or a segment.

\section{Phonemes and Segments/overlap}

Within the spoken form of English, many concepts are identified in the fields of phonetics and phonology-two main processes are dealt with: phonemics and segmentation which tackle phonemes and segments, respectively. Peter Roach (2002: 57 ff) introduces phonemes as the fundamental units of phonology; virtually all theories of phonology hold that n.) the spoken language can be broken into a string of sound units (phonemes), and that each language has a relatively small fixed set of these phonemes. Most of them can be put into groups, for example/p $\mathrm{t} \mathrm{k} \mathrm{b} \mathrm{d} \mathrm{g/.} \mathrm{When} \mathrm{the} \mathrm{importance} \mathrm{of} \mathrm{the} \mathrm{phoneme} \mathrm{became} \mathrm{widely}$ accepted, in the 1930's and 40's, many attempts were made to develop scientific ways of establishing the phonemes of a language and listing each phoneme, this is known as phonemics.

As it has been always assumed by phoneticians that any stretch of speech is composed of smaller pieces in different selections and on different orders. Those units are called phonemes (from the Greek phénéma, 'sound'). This term dates as far back as the work of the nineteenth-century Polish linguist Jan Baudouin de Cowhiay. The phoneme is a concept used in phonology, which is why the subdiscipline is sometimes called phonemics in the US (Skandera and Burleigh, 2005: 19). 
However, the definition of a phoneme has been interpreted in many views. A view defines phoneme as the smallest distinctive unit in a specific language e.g., tip in English realizes three phonemes/t// $/ / \mathrm{p} /$. By 'distinctive' is meant having a contrastive function e.g./ I p/is different from/s I p/in English the substitution of one sound type for another results change of word meaning (Carr, 2008:1122). This view is rather a concrete conception of the phoneme. A variant on this concrete view is that a phoneme is a set, or family, of distinct speech sound-types that count as 'the same thing'. This variant version is more abstract than the idea that phonemes are literally sounds, since sets are not sounds; they are abstract, in some sense. Another view is more mentalistic than this. This view states that phonemes are not sounds and cannot be heard, since they are mental categories. The first two views are based on realism. A third view takes phonemes to be no more than theoretical constructs, devised -sound patterns in a specific language. This view is based on instrumentalism. Some phonologists, such as Trubetzkoy, have argued for a functional View of phonemes; for Trubetzkoy, one must identify phonemes on the basis of their function in the phoneme system of a particular language (ibid).

Laver (1994:41-2) defines phoneme in two perm The first is: "The speech sounds are said to be manifestation of different phonemes in a given accent of a language when they act as the basis of a contrastive opposition that distinguishes a pair of words of identical phonological structure, differing in the systemic choice made at a single place in that structure." The second part is: "speech sounds regularly occurring in a number of different structures and contexts may be classified as members of a given phoneme if their occurrences are in complementary distribution". Tim $(2007: 106)$ states that a phoneme may well represent several phonetically similar or phonologically related sounds, but the relationship may not be phonetically obvious, which is one of the problems with this conceptual scheme.

From what has been mentioned, the overlap and the misusage of the term becomes very clear; in addition, the term segment is ignored by the time it should be replaced by the term phoneme in some of the definitions mentioned. So, what is a segment and how it differs from the phoneme? A segment refers to any discrete unit that can be identified either at physically or auditorily in the stream of speech (Crystal, 2003: 408). Segmentation is a process, used in descriptive analysis or in speech processing, by which a form of representation at one level is divided into a succession of discrete units, i.e. splitting a representation of continuous speech into successive phonemes (Matthews, 2007:359). Lodge (2009: 97) states that segmentation is a convenient way of conceptualizing speech for further phonological analysis.

\section{The analysis of phonetic \& phonological approach of segments \& phonemes}

Hewlett and Beck (2006: 14) state that in a segmental approach to speech analysis, the first task of the listener is to identify the separate sounds that make up an utterance. Each sound is called a segment, and prom of deciding where the boundaries are between the separate sounds is known as segmentation. Laver (1994: 102-3) claims two approaches to segmentation, which are the parametric approach and the linear approach. In the first one, each component of vocal performance is treated as a parameter whose value is in a state of constant potential change, e.g. the pitch of voice and the loudness of the voice. In the second approach, each unit can be characterized in terms of representative values shown during the production of that unit by the individual phonetic components making up the performance.

The term segment is sometimes substituted by another term called phone (from the Greek phōné 'voice'); despite the overlap, there are important points must be mentioned to set up the distinctions between phonemes and segments. Skandera and Burleigh (2005:19) state that it is important to remember that phonemes are abstract, ideal sounds that are never produced and never heard (i.e. mental forms). When these abstract forms (in the mind) are sequenced into strings of sounds, they are called segments, i.e. segments are different realizations of phonemes pronounced in actual speech e.g., $/ 1 /$ is a phoneme that has different versions or other realizations in actual speech that are clear [1], dark [f], syllabic [1] and devoiced [1] which are further called allophones. The other point is that phonemic symbols are enclosed within//; whereas the segments or the phonetic symbols or phones are enclosed within [].

Hewlett and Beck (2006: 15) state that it is important to remember that segments do not exist in isolation and that the production of each one will be affected by its neighbors and by the context and style of speech. Phonemes, on the other hand, stand individually to produce minimal pairs. In short; it is possible to say that when a phoneme functions in the actual speech it becomes a segment.

Phoneticians disagree about segments: when we analyze an utterance we can identify a number of phonological and grammatical elements, partly as a result of our knowledge of the language. Consequently, we are able to write down something we hear in words separated by spaces, and (with proper training) transcribe with phonemic symbols the sounds that we hear. However, when we examine speech sounds within connected speech closely, we find many cases where it is difficult to identify separate sound units (segments) that correspond to phonemes, since many of the articulatory movements that create the sounds tend to be continuous rather than sharply switched. For example, sequences of fricative often overlap, so that it is difficult or impossible to split the sequence $\left[\int \mathrm{s}\right]$ in fish soup [fi $\left.\int \mathrm{su}: ? \mathrm{p}\right]$. As a result some people believe that dividing speech up into segments (segmentation) is fundamentally misguided; the opposite View is that segmentation appears to be possible in most cases, and where seem to be aware of segments in their speech. (ibid)

\section{Conclusion}

The solutions to the problems that the students face about differentiating between a phoneme and a segment are maintained in a number of factors: it is known that students have to listen to native speakers, e.g. listening comprehension; and communicate throughout any communicative teachable channel. It is important to know that the problems arise 
throughout: transcription methods; the scientific medial approach which affects the as the integration of pronunciation are the clues to avoid the overlap encoding and decoding processes; and the physiology of sound waves as well between phonemes and segments. To clarify the overlap between segments and phonemes, the following table shows the simple differences between the two:

\begin{tabular}{|c|c|}
\hline Phoneme & Segment \\
\hline $\begin{array}{l}\text { It is assumed that any } \\
\text { stretch of speech is } \\
\text { composed of smaller } \\
\text { pieces in different } \\
\text { selections and on } \\
\text { different orders. } \\
\text { Those units are called } \\
\text { phonemes } \\
\text { A mental and an abstract } \\
\text { concept. } \\
\text { Phoneme has one form } \\
\text { or shape (non-variable) } \\
\text { e.g., /p/ } \\
\text { Phonemes are isolated } \\
\text { individual sounds. } \\
\text { Phonemes are } \\
\text { represented by } \\
\text { phonemic transcription } \\
\text { that is enclosed within } \\
\text { slashes // }\end{array}$ & $\begin{array}{l}\text { In a segmental approach to speech } \\
\text { analysis the first task of the listener } \\
\text { is to identify the separate sounds } \\
\text { that make up an utterance. Each } \\
\text { sound is called segment, and the } \\
\text { process of deciding where the } \\
\text { boundaries are between the separate } \\
\text { sounds is known as segmentation } \\
\text { The concrete and the actual } \\
\text { representation of a phoneme. } \\
\text { Segments appear in different forms } \\
\text { for the same phoneme e.g., [ph] } \\
\text { or [?p]. } \\
\text { Segment: never come in isolation } \\
\text { they are always in } 5 \text { a e isolated } \\
\text { individual sounds combinations to } \\
\text { form utterances. } \\
\text { Segments are represented by the } \\
\text { Phonetic transcription (allophonic } \\
\text { transcription) that is enclosed } \\
\text { within square brackets }\end{array}$ \\
\hline
\end{tabular}

Such a subject is very necessary for our students (Iraqi MA \& postgraduates) because phonetics \& phonology are inseparable; the students have to realize that phonetics is the raw material (the core to phonology

\section{REFERENCES}

Brosnahan, L.F., and Malmberg, B. (1970). Introduction to phonetics. London: Heffer and Sons Ltd, Cambridge.

Carr, P (2008). A Glossary of Phonology. Edinburgh: Edinburgh University Press.

Crystal, D. (2003). A Dictionary of Linguistics and Phonetics. London: Blackwell Publishing.

Hewlett, N. and J. Beck (2006). An Introduction to the Science of Phonetics. New Jersey: Lawrence Erlbaum Associates, Inc. Publishers.

Laver, J. (1994). Principles of Phonetics. Cambridge University Press.

Lodge, K. (2009). A Critical Introduction to Phonetics. London: Continuum International Publishing Group.

Matthews, P. H. (2007). The Concise Dictionary of Linguistics. Oxford: Oxford University Press.

Nasr, R. (1997). Applied English Phonology for ESL/EFL Teachers. New York: University Press of America.

Skandera, P. and Burleigh, P. (2005). A Manual of English Phonetics and Phonology. Berlin: Narr Francke.

Tim, R. (2007). Dictionary of Phonetics. Delhi: IVY Publishing House. 